\title{
Formation and evolution of porosity during high temperature creep of a nickel-based single crystal superalloy
}

\author{
Weiwei Liu ${ }^{1, *}$ Yuanyuan Guo $^{1}$, Mai Zhang ${ }^{1}$, and Jian Zhang ${ }^{1}$ \\ ${ }^{1}$ Science and Technology on Advanced High Temperature Structural Materials Laboratory, Beijing \\ Institute of Aeronautical Materials, Beijing 100095, P.R. China
}

\begin{abstract}
A Re-containing single-crystal superalloy was used to research the high temperature low stress creep behavior. Transmission electron microscope, scanning electron microscope and some other research methods are employed. The results and analysis are summarized below: Two mechanisms for the steady creep are found in this experiment. The volume fraction of pores after creep test at $1100^{\circ} \mathrm{C}$ increased more than 2 times compared with that before test, but the increasing at $1000^{\circ} \mathrm{C}$ is relatively small, which reveals that temperature has an great influence on the formation of pore during creep; There are two types of pores associated with fracture during the creep process. One is the casting shrinkage located between the interdentritic, which is formed in the solidification of the alloy. Another type of pore is nucleated and growing during the creep deformation.
\end{abstract}

Key words: single crystal superalloy ; creep ; dislocation ; porosity

Nickel-based superalloys have high temperature fatigue and creep strength, and also have good thermal corrosion resistance, so they are widely used in making turbine blades

*Corresponding author: liuww_80@sina.com 
and guide blades of gas turbines. Under actual service conditions, blades are subjected to high temperature and high stress. Especially during engine operation, high temperature combined with centrifugal stress will lead to creep deformation of blades, which will seriously affect the service life of blades ${ }^{[1,2]}$. With the increase of turbine temperature in advanced aeroengines, high temperature creep fracture has been one of common failure modes of single-crystal(SC) superalloy blades. Creep behaviour of Ni-based SC superalloys under typical condition has been researched extensively. In order to design and predict the service life of components reasonably, the creep behavior of superalloy needs to be fully understood and mastered. In the past decades, the creep behavior of monocrystalline superalloys has received extensive attention. The results show that the creep behavior and fracture mechanism of SC superalloy is affected by experimental condition, including temperature, loading mode, stress and other factors. With the change of these factors, the creep behaviour and deformation mechanism show different patterns ${ }^{[3-16]}$.

In this paper, the high temperature creep of Ni-base SC superalloy under low applied stress at $1100^{\circ} \mathrm{C}$ and $1000^{\circ} \mathrm{C}$ was studied. The creep behaviour, fracture characteristics and creep deformation, especially the formation and growth of porosity in monocrystalline alloys were systematically researched and analysed. The results can provide experimental data for the application of SC alloys at high temperature and optimize the creep theory of Ni-base SC superalloys.

\section{Experimental procedure}

The material used in this article is a first-generation Ni-base SC superalloy containing the chemical components of Ni-Cr-W-Ta-Al-Co-Ti-Mo system. A series of constant load tensile creep experiment were carried out on a creep machine with $120 \sim 220 \mathrm{MPa}$ stress. The test temperatures were $1000^{\circ} \mathrm{C}$ and $1100^{\circ} \mathrm{C}$ respectively. The creep strain was measured by an extensometer attached to the shoulder of the creep sample, with a measurement accuracy of $5 \times 10^{-4} \sim 5 \times 10^{-5}$. Most of the specimens were tensile fracture, and some of the specimens were subjected to the creep interruption experiment to observe the microstructure.

\section{Results and discussion}

\subsection{Creep behaviour}



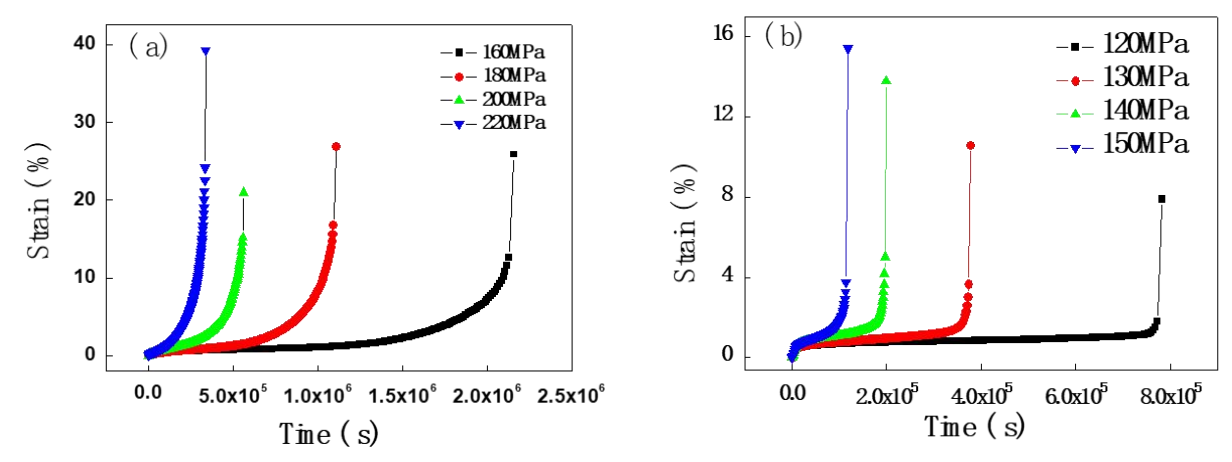

Fig. 1 Creep curves under different condition: (a) $1000{ }^{\circ} \mathrm{C}$ and (b) $1100{ }^{\circ} \mathrm{C}$

Creep curves of the alloys at different stress at two temperatures are shown in figure 1. As can be seen from the figure, its high-temperature creep behavior mainly shows the following characteristics:

(1) Under the test conditions of $1000^{\circ} \mathrm{C}$ and $1100^{\circ} \mathrm{C}$, the creep curve shows the creep characteristics of three stages: initial creep(first stage), steady creep(secondary stage) and accelerated creep(third stage).

(2) When temperature increases from $1000^{\circ} \mathrm{C}$ to $1100^{\circ} \mathrm{C}$, the creep elongation decreases significantly. At $1000^{\circ} \mathrm{C}$, the elongation is $20 \% \sim 40 \%$. The elongation at $1100{ }^{\circ} \mathrm{C}$ is $8 \% \sim$ $16 \%$, which is smaller than that of $1000^{\circ} \mathrm{C}$.

(3) At $1000^{\circ} \mathrm{C}$, the creep strain rate increased slowly after the alloy entered the third phase of creep. At $1100^{\circ} \mathrm{C}$, the strain rate of creep increased quickly after the start of the accelerated stage, then, rupture occurred in a very short time.

\subsection{Microstructural evolution}

It's can be seen from Fig. 2, during the creep experiment at high-temperature ranging from both $1100{ }^{\circ} \mathrm{C}$ to $1000{ }^{\circ} \mathrm{C}$, raft of directional coarsening of $\gamma^{\prime}$ phase occurred. The microstructure of creep interruption specimen indicates that directional coarsening of $\gamma^{\prime}$ phase occurs rapidly in the initial stage of creep, and raft structure has been formed in early stage of creep steady state. During the post-stage of creep test, the thickness of $\gamma^{\prime}$ raft structure increases by degrees and the raft structure begin to interconnect with each other, which causes the topological inversion of $\gamma^{\prime}$ phase surrounding $\gamma$ matrix in the middle and post stages of creep. 

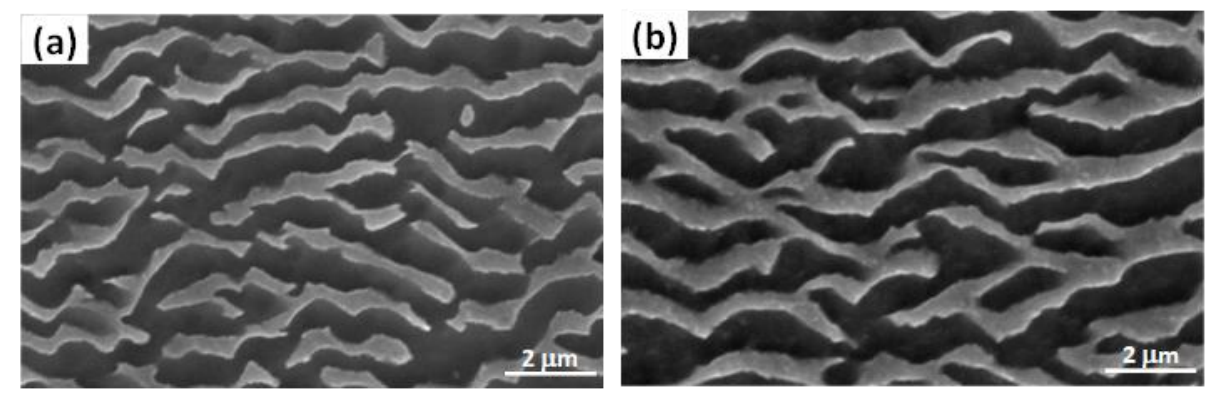

Fig. 2 Directional coarsening of $\gamma^{\prime}$ phase after high-temperature creep rupture
(a) $1000^{\circ} \mathrm{C}-200 \mathrm{MPa}$; (b) $1100^{\circ} \mathrm{C}-130 \mathrm{MPa}$

In the experiments of $1100{ }^{\circ} \mathrm{C}$ and $1000{ }^{\circ} \mathrm{C}$. The dislocation TEM observation shows that regular dislocation network at the $\gamma / \gamma^{\prime}$ interface is quickly formed because of the reaction between dislocations. It is can be seen that $\gamma^{\prime}$ phase was cut by superlattice dislocation in secondary stage of creep at both $1000{ }^{\circ} \mathrm{C}$ and $1100{ }^{\circ} \mathrm{C}$ (Fig. 3a and b). Which is the main deformation mechanism of steady-state creep. By comparison, there are much more dislocations cutting into $\gamma^{\prime}$ phase. However, there are only a few dislocations cutting into $\gamma^{\prime}$ phase under $1100^{\circ} \mathrm{C}$ and lower stress, and show a single form of screw dislocations. Which is main difference between $1000^{\circ} \mathrm{C}$ and $1100{ }^{\circ} \mathrm{C}$ test on the creep deformation mechanism.

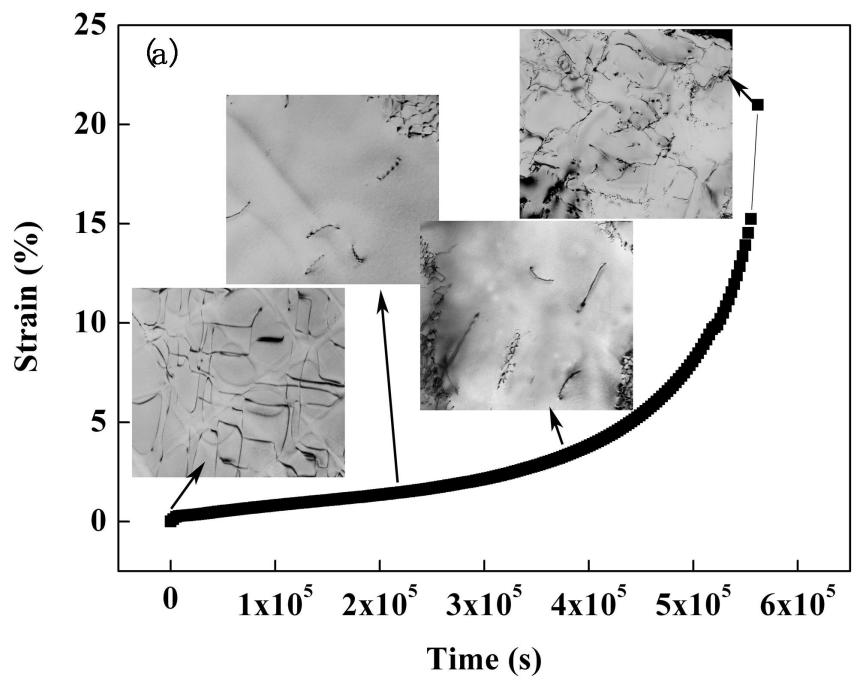




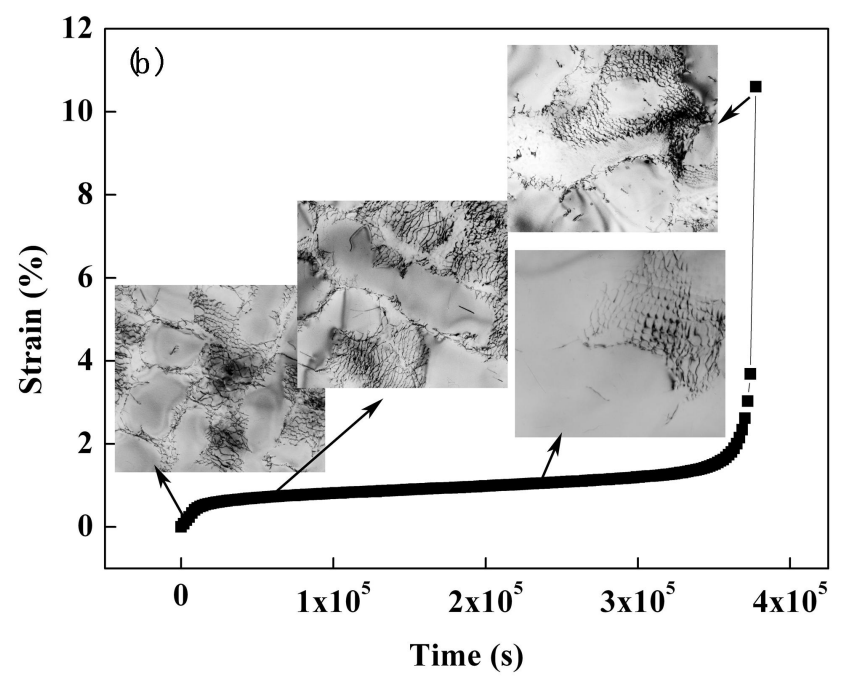

Fig. 3 Combination of creep curves with microstructural evolution during the creep

(a) $1000^{\circ} \mathrm{C}-200 \mathrm{MPa}$; (b) $1100^{\circ} \mathrm{C}-130 \mathrm{MPa}$

\subsection{Behaviour of porosity and creep rupture}

As seen from Fig. 4 , the fracture morphology features after creep rupture in this test show slight different between $1000{ }^{\circ} \mathrm{C}$ and $1100{ }^{\circ} \mathrm{C}$. There are abundant square facets on creep fracture surface, the orientation of planar edge is along $<110>$ direction. Small circular holes can be seen at the center of planes, and which are the origin of cracks. In tests of $1100^{\circ} \mathrm{C}$, the border line of square facets in the fracture gradually becomes irregular and unsharp, the number of crack initiation points strikingly increases.
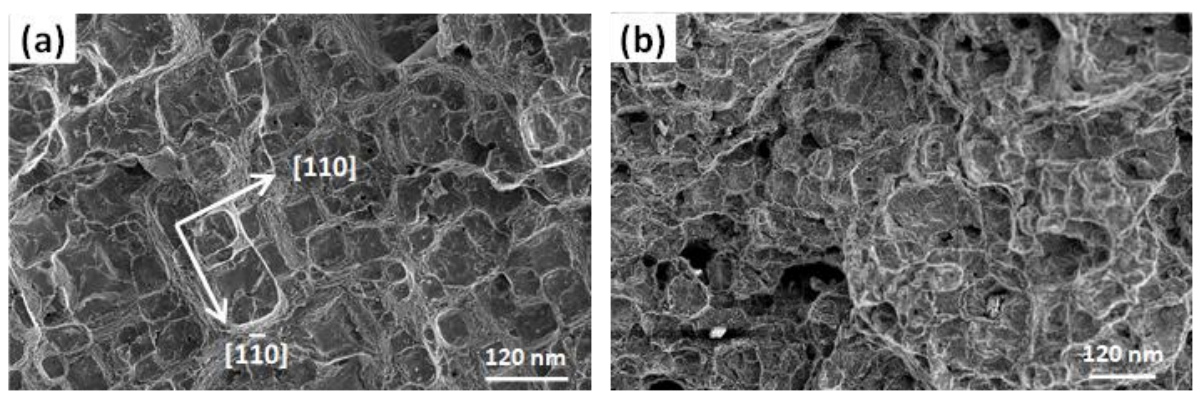

Fig. 4 Fracture morphology of after creep rupture

Longitudinal microstructure morphology near the fracture after creep test presented in Fig. 5 shows that a large number of micro-cracks exist in the necking zones near the fracture. The initiation and growth of these micro-cracks are the main controlling factors of 
alloy fracture. The main defects in SC alloy are casting shrinkage in the interdendritic region. It can also be seen from Fig. 5 that the main origin of micro-cracks is casting pores in the interdendritic region under the condition of $1000^{\circ} \mathrm{C}$ and $200 \mathrm{MPa}$. However, the number of micro-cracks is obviously more than that of the former under the condition of $1100^{\circ} \mathrm{C}$ and $130 \mathrm{MPa}$. Further observation shows that micro-cracks are distributed throughout the interdendritic and dendritic regions. This indicates that there are new creep pores formed in addition to casting pores in the process of creep at $1100^{\circ} \mathrm{C}$, which might induce the initiation of cracks. The comparison of the volume fraction of pores away from the fracture with that of pre-deformation alloys presented in Table 1 shows that the volume fraction of pores after creep test at $1100{ }^{\circ} \mathrm{C}$ increased more than 2 times compared with that before test, but the increasing at $1000{ }^{\circ} \mathrm{C}$ is relatively small, which reveals that temperature has an great influence on the formation of pore during creep, and verified by the observation of the longitudinal microstructure morphology under other stress conditions at $1000{ }^{\circ} \mathrm{C}$ and $1100^{\circ} \mathrm{C}$.
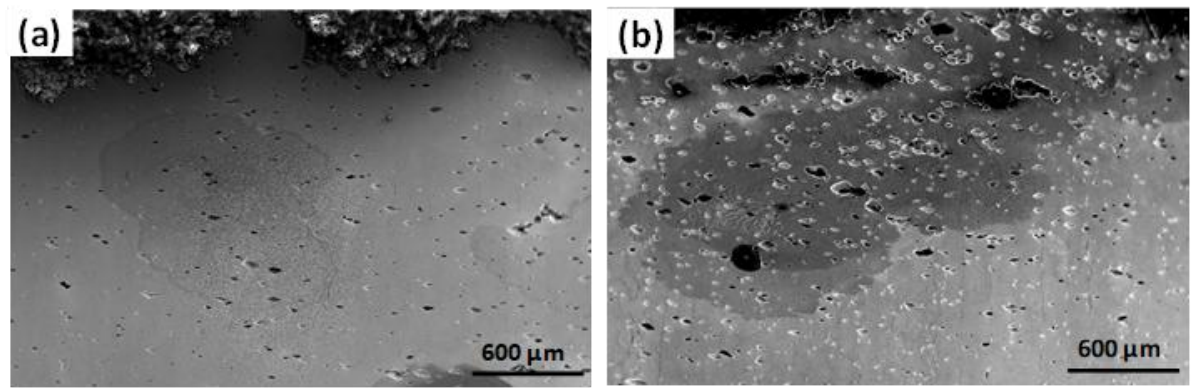

Fig. 5 Longitudinal microstructure morphology of fracture after creep fracture

Table 1 Comparison of pore fraction before and after deformation

\begin{tabular}{cccc}
\hline & Undeformed & $1000{ }^{\circ} \mathrm{C} 、 200 \mathrm{MPa}$ & $1100{ }^{\circ} \mathrm{C} 、 130 \mathrm{MPa}$ \\
\hline Porosity (\%) & 0.17 & 0.21 & 0.37 \\
\hline
\end{tabular}

In order to investigate the high temperature creep fracture mechanism of the alloy, it is necessary to further analyze the pores that cause the crack initiation. As mentioned above, there are two types of pores associated with fracture during the creep process. One is the casting shrinkage located between the interdentritic, which is formed in the solidification of the alloy. In this work, it is defined as I-type pore. Another type of pore is nucleated and growing during the creep deformation, which is defined as II-type pore.

the variation of the I-type pore during creep is presented in Fig. 6. It can be seen that the I-type pore grows with the increase of creep deformation and gradually evolves into a 
polyhedral shape, and its surface orientation conforms to a certain crystallographic law. At $1100{ }^{\circ} \mathrm{C}$, the cross-section of pore is mostly pentagonal orhexagonal, with plane paralleling to $\{100\}$ plane or $\{110\}$ plane, However, the cross-section of pore is mostly quadrilateral at $1000{ }^{\circ} \mathrm{C}$, with plane paralleling to $\{100\}$ plane. Combined with the analysis of specimen under other conditions, it shows that the higher the experimental temperature, the higher the degree of polyhedralization of pore and the clearer the polyhedral contour. The reason for the above phenomenon is that the surface energy has obvious anisotropy at higher experimental temperatures, which is the characteristic of pores when grown up in the form of vacancy aggregation. From the micro-fracture mechanism, the structure at the apex angle of the polyhedral pore is equivalent to a lot of micro-notches, and the stress concentration effect around the notch makes it easy to crack during creep process, especially when the specimen is necked and the stress is increased. The initiation of microcracks at the corners of the pore, and its connection with surrounding cracks after expansioncan be seen in Fig. 7 . The degree of polyhedralization of pores is low at $1000^{\circ} \mathrm{C}$, and the phenomenon of crack initiation at sharp corners is not obvious compared with the experiment at $1100{ }^{\circ} \mathrm{C}$.
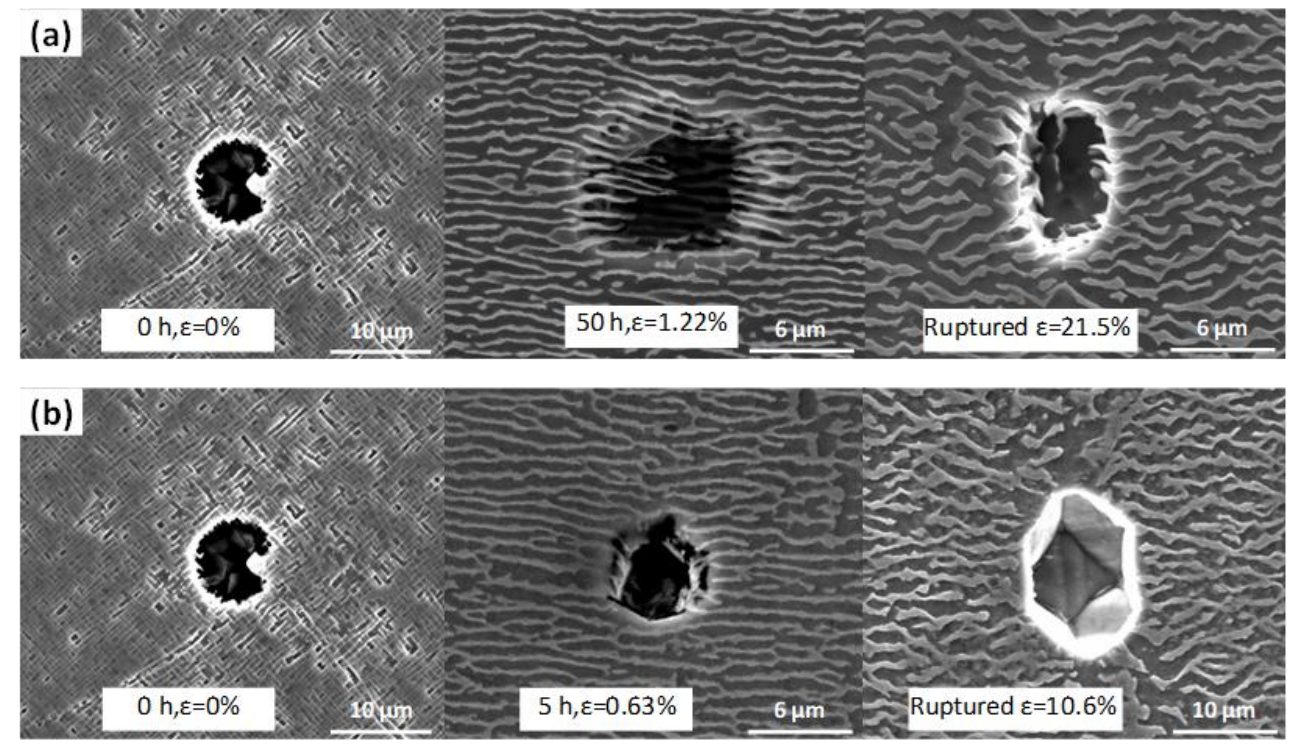

Fig. 6 Evolution of I-type pores during creep 

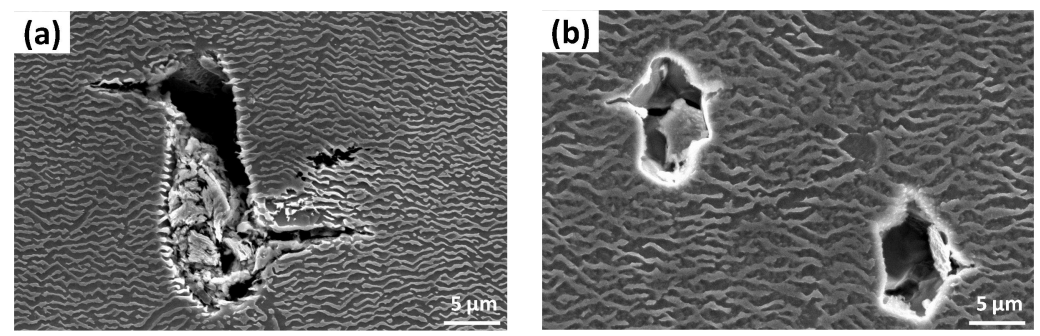

Fig. 7 cracking of I-type pore in the third stage of creep

Fig. 8 shows the initiation and cracking of II-type pore during creep. II-type pores are more likely to occur at the $\gamma / \gamma^{\prime}$ phase interface of the dendritic region and gradually grow up during the creep process. At $1000^{\circ} \mathrm{C}$, the number of II-type pores is small due to poor atom diffusion capacity, and no cracking is observed in the third stage of creep, so the impact on the creep process is minimal. In contrast, the growth trend of II-type pores at $1100{ }^{\circ} \mathrm{C}$ is obvious. In the post stage of creep, the pores in the necking region can be extended along any path in the $\gamma / \gamma^{\prime}$ structure under stress, and together with I-type pore to cause the rapid cracking, which is also directly causing the small proportion, faster creep rateand small total elongation in thethird stage of creep test at $1100{ }^{\circ} \mathrm{C}$.

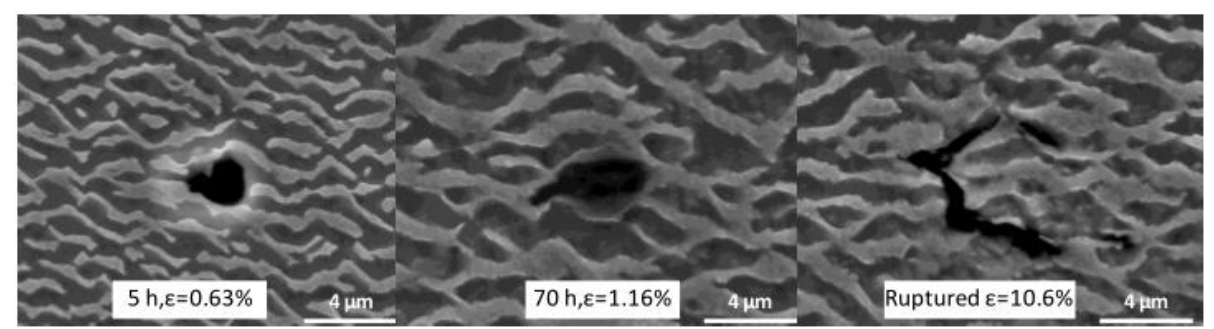

Fig.8 Formation and cracking of II-type pores during creep at $1100^{\circ} \mathrm{C}$

\subsection{Analysis and discussion}

The creep behavior of SC superalloys usually shows distinct deformation and fracture mechanisms according to changes in stress and temperature. In summary, under the condition of low temperature and high stress, dislocations will be cut into the $\gamma^{\prime}$ phase by stacking faults, dislocation pairs or combination of both under high applied stress. With the increase of temperature and the decrease of stress level, the diffusion ability of elements in alloys gets enhanced, and the dislocations are more likely to be deformed by crossing the precipitated phase in such a way as climbing, Orowan bypassing, etc. When the experimental temperature is further increased above $1000{ }^{\circ} \mathrm{C}$, the creep mechanism will change again. The micro-deformation characteristics of creep process in this work have a 
certain degree of representativeness, and the main manifestations are as follows: the movement of dislocations in the matrix and the formation of dislocation networks, superlattice dislocation cutting $\gamma^{\prime}$ precipitates, directional coarsening (shaped raft) of $\gamma^{\prime}$ phase and initiation and growth of pores.

The results of creep tests in this work show that there are more dislocations cutting $\gamma^{\prime}$ phase during $1000{ }^{\circ} \mathrm{C}$ creep, which is the result of the larger applied stress ranges. In the post stage of creep steady state, the coarsening of $\gamma^{\prime}$ phase lead $s$ the $\gamma / \gamma^{\prime}$ dual-phase structure to be topologically inverted, the raft structures are interconnected and structurally transformed into the matrix phase, and the superlattice dislocations entering the interior of raft structures can be move continuously without interface hindrance, which causes the deformation of alloy to be intensified and accelerates the creep into the third stage. At the same time, It can be seen from the observation of volume fraction of pores and the longitudinal section of fracture, the increase of total pores at $1000{ }^{\circ} \mathrm{C}$ creep is limited, indicating that the interface dislocations climbing mechanism is suppressed at $1000{ }^{\circ} \mathrm{C}$, and the main deformation mechanism after creep steady state is dislocations cutting $\gamma^{\prime}$ phase. In contrast, there is only a small amount of superlattice dislocations formed at $1100{ }^{\circ} \mathrm{C}$ creep, indicating that the stress ranges of $120-150 \mathrm{MPa}$ are not enough to press a large amount of dislocations into $\gamma^{\prime}$ phase. On the other hand, pre-existing pores in the alloy undergo significant polyhedral growth, and a large number of new creep pores appear, which means that the diffusion capacity of elements is significantly improved after the temperature raising to $1100{ }^{\circ} \mathrm{C}$, and the interface dislocations climbing mechanism begins to become the main deformation mechanism in the middle and post stage of creep. Only few amounts of deformations occur during the whole creep steady state, which indicates that the contribution of the interface dislocations climbing mechanism to creep deformation is small, and its main influence is extruding vacancies and continuous accumulation at pores. When the cross-sectional area of pores reaches critical value, the alloy rapidly enters the third stage and fractures. The simultaneous fracture of both types of pores also causes the elongation of the alloy to be significantly reduced.

\section{3 conclusions}

In this article, a Ni-based SC superalloy was used to research the high temperature creep under low applied stress at $1100{ }^{\circ} \mathrm{C}, 120-150 \mathrm{MPa}$, and $1000^{\circ} \mathrm{C}, 160-220 \mathrm{MPa}$. The main findings of the research are summarized as below:

1. At $1000{ }^{\circ} \mathrm{C}$, the accelerated stage of creep lasts longer and deformation rate changes slowly, the elongation is obviously larger than $1100^{\circ} \mathrm{C}$. The deformation rate of the accelerated stage quickly increases and ruptures within a short time at $1100^{\circ} \mathrm{C}$. By contrast, the total elongation decreases by around $50 \%$ compared with that of $1000{ }^{\circ} \mathrm{C}$; 
2. The volume fraction of pores after creep test at $1100{ }^{\circ} \mathrm{C}$ increased more than 2 times compared with that before test, but the increasing at $1000{ }^{\circ} \mathrm{C}$ is relatively small, which reveals that temperature has an great influence on the formation of pore during creep;

3. There are two types of pores associated with fracture during the creep process. One is the casting shrinkage located between the interdentritic, which is formed in the solidification of the alloy. Another type of pore is nucleated and growing during the creep deformation.

\section{References}

[1] R. C. REED. The superalloys: Fundamentals and applications. (Cambridge University Press, 2006)

[2] Y. TANG, M. HUANG, J. XIONG, et al. Acta Materialia, 126 (2017)

[3] S. MA, X. LV, J. ZHANG, et al. Journal of Alloys and Compounds, 743 (2018).

[4] S. ZHANG, S. G. TIAN, et al. Rare Matel Materials and Engineering, 39 (2010).

[5] Z. X. WEN, D. Zhang, S. Li, et al. Journal of Alloys and Compounds, 692 (2017).

[6] B. SHOLLOCK, J. BUFFIERE, R. CURTIS, et al. ScriptaMaterialia, 36 (2017).

[7] C. M. F. RAE, R. C. REED. Actaclia, 55 (2007).

[8] S. TIAN, X. DING, Z. GUO, et al. Materials Science and Engineering: A, 594 (2014).

[9] P. WOLlgRAmM, D. BÜRGER, A. B. PARSA, et al. High Temperature Technology, 33 (2016).

[10] M. HUANG, L. ZHUO, J. XIONG, et al. Philosophical Magazine Letters, 95 (2015).

[11] T. M. POLLOCK, A. S. ARGON. Acta Metallurgica Et Materialia, 40 (1992).

[12] H. S. M. HAFEZ, G. EGGELER, D. RAABE. Acta Materialia, 61 (2013).

[13] M. PROBST-HEIN, A. DLOUHY, G. EGGELER. Acta Materialia, 47 (1999).

[14] J. X. ZHANG, J. C. WANG, H. HARADA, et al. Acta Materialia, 53 (2005).

[15] M. HUANG, Z. CHENG, J. XIONG, et al. Acta Materialia, 76 (2014). 